УДК 621.315 .592

DOI: https://doi.org/10.36910/6775-2313-5352-2019-14-13

С.В. Луньов ${ }^{1}$, Ю.А. Удовицька ${ }^{1}$, М.В. Хвищун ${ }^{1}$, С.А. Мороз ${ }^{1}$, В.Т. Маслюк ${ }^{2}$

${ }^{1}$ Луцький національний технічний університет, вул. Львівська 75, м. Луцьк, 43018, Україна, luniovser@ukr.net

${ }^{2}$ Інститут електронної фізики НАН України, вул. Університетська 21, м. Ужгород, 88017, Україна, volodymyr.maslyuk@gmail.com

\title{
ТЕХНОЛОГІЯ ОДЕРЖАННЯ ЧУТЛИВОГО ЕЛЕМЕНТА ДЛЯ ДАТЧИКА ІНФРАЧЕРВОНОГО ВИПРОМІНЮВАННЯ
}

Встановлено на основі вимірювань інфрачервоної Фур'є-спектроскопії та ефекту Холла, що основними типами радіаційних дефектів в опромінених електронами монокристалах кремнію є кисневмісні комплекси, до складу яких входить міжвузловий вуглець та легуюча домішка. Досліджувані монокристали кремнію в процесі вирощування за методом Чохральського легувались домішкою фосфору, конщентрацією $N_{d}=2,2 \cdot 10^{16} \mathrm{~cm}^{-3}, \quad$ та в подальшому опромінювались при кімнатній температурі потоком електронів $1 \cdot 10^{17} \mathrm{eл} . / \mathrm{cm}^{2} 3$ енергією 12 МеВ. Показано, що для таких технологічних умов виромування та опромінення монокристалів кремнію потоком швидких електронів є досить ефективним утворення в об'ємі даних монокристалів А-центрів, додатково модифікованих домішкою фосфору (комплексів $\left.V O_{i} P\right)$. Радіачійна обробка досліджуваних монокристалів кремнію дозволила підвищити їх коефіиієнт фоточутливості при кімнатній температурі більще як в 2 рази для довжини хвилі інфрачервоного випромінювання $\lambda \sim 11,6$ мкм, що відповідає поглинанню радіачійними дефектами, яким належать комплекси $C_{i} O_{i}$ (міжвузловий вуглець - кисень). Показано, щэо при температурах нижчих за кімнатну з'являється ще одна смуга поглинання при $\lambda \sim 11,3$ мкм, щуо відповідає комплексам $V O_{i} P$. Запропонована технологія одержання монокристалів кремнію може бути використана для створення на їх основі елементів інфрачервоної техніки для довжин хвиль $\lambda \sim 11,6$ мкм та $\lambda \sim 11,3$ мкм., які зможуть функціонувати в широкому діапазоні температур.

Ключові слова: монокристали кремнію, радіаційні дефекти, фоточутливість, Ацентри, інфрачервона Фур'є-спектроскопія, ефект Холла.

Вступ. Одним з найбільш перспективних напрямків розвитку елементної бази сучасної мікро-та наноелектроніки $\epsilon$ розробка різних напівпровідникових датчиків. Серед таких приладів значна увага приділяється сенсорам інфрачервоного випромінювання, які використовуються для виявлення зон високих температур і можливих осередків виникнення пожеж, зондування навколишнього середовища на предмет забруднення шкідливими та отруйними речовинами, ранньої діагностика запальних, ракових та інших захворювань, визначення зон теплових втрат, вирішення задач національної безпеки та обороноздатності країни. Цілеспрямований вплив різних фізико активних полів, таких як радіаційні, температурні, електричні, магнітні, та легування різного роду домішками дозволяє одержувати на основі напівпровідникових матеріалів різні електронні прилади та сенсори функціональної електроніки 3 наперед прогнозованими характеристиками Інтенсивний розвиток напівпровідникової електроніки та напівпровідникового матеріалознавства сприяє вдосконаленню властивостей вже як існуючих, так i пошуку та розробки нових напівпровідникових матеріалів. Такий напівпровідниковий матеріал, як кремній, незважаючи на всебічну вивченість його властивостей, був і залишається основним матеріалом електронної техніки [1].

Модифікація фізичних властивостей напівпровідників за рахунок радіаційної обробки в багатьох випадках може служити ефективним технологічним інструментом, який дозволяє отримувати якісні напівпровідникові матеріали, істотно вдосконалити та здешевити виробництво багатьох типів напівпровідникових приладів $[2,3]$. В даному сенсі монокристалічний кремній 3 дефектами структури, які можна створити цілеспрямовано за рахунок радіаційного опромінення, може бути перспективним матеріалом для конструювання сенсорів інфрачервоного випромінювання.

Експериментальні результати та їх обговорення. Для монокристалів кремнію, вирощених за методом Чохральського, 3 малим вмістом легуючих домішок, основними радіаційними дефектами є А-центри, дивакансії та комплекси $\mathrm{C}_{\mathrm{i}} \mathrm{O}_{\mathrm{i}}[4,5]$. Утворення при 
електронному або $\gamma$ - опромінені Е-центрів, дивакансій, комплесів $\mathrm{C}_{\mathrm{i}} \mathrm{C}_{\mathrm{s}}$ характерним $є$ для кремнію, вирощеного методом безтигельної зонної плавки $[4,6]$. Проте, мало вивченим на сьогодні є дефектоутворення в кремнії з середнім та сильним рівнем легування при енергіях електронного опромінення більше $10 \mathrm{MeB}$. В даному випадку концентрація легуючої домішки буде суттєво впливати на ефективність введення при опроміненні вище розглянутих дефектів і також на ймовірність утворення нових радіаційних дефектів. Також в опроміненому кремнії швидкими електронами 3 енергією $\mathrm{E}>10 \mathrm{MeB}$ поряд 3 точковими дефектами починають утворюватись області розвпорядкування [7]. Тому метою даної роботи було дослідження впливу опромінення швидкими електронами 3 енергією $12 \mathrm{MeB}$ на фоточутливість монокристалів кремнію, легованих домішкою фосфору. Концентрація легуючої домішки фосфору для досліджуваних зразків кремнію, вирощених за методом Чохральського, складала $\mathrm{N}_{\mathrm{d}}=2,2 \cdot 10^{16} \mathrm{~cm}^{-3}$. Для ідентифікації природи утворених радіаційних дефектів проводились вимірювання інфрачервоної Фур'є-спектроскопії та ефекту Холла. На рис. 1 представлено спектри поглинання для монокристалів $\mathrm{n}-\mathrm{Si}$, опромінених потоком електронів $1 \cdot 10^{17}$ ел./см ${ }^{2}$.

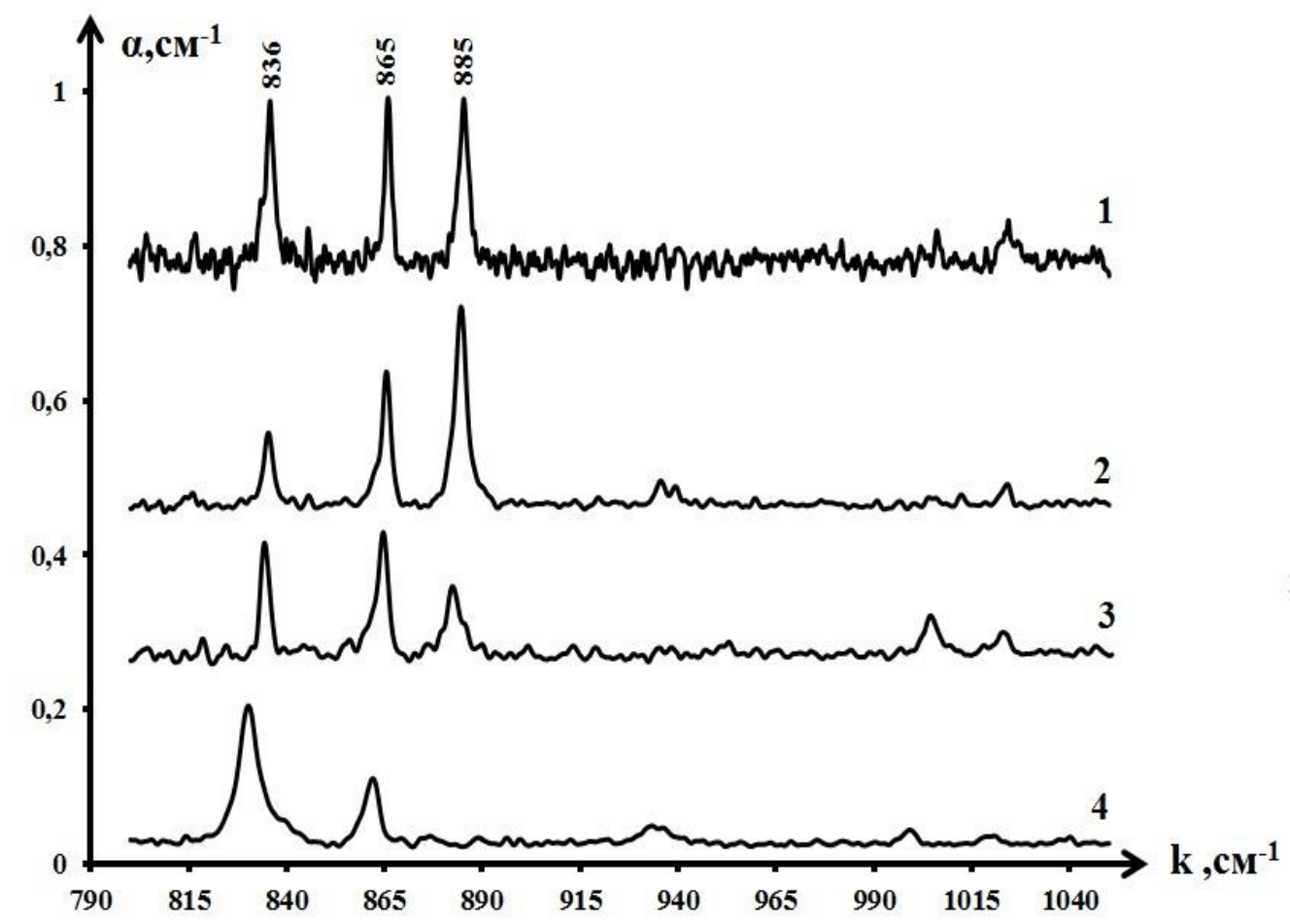

Рис. 1. Спектри поглинання для опромінених монокристалів кремнію потоком електронів $1 \cdot 10^{17}$

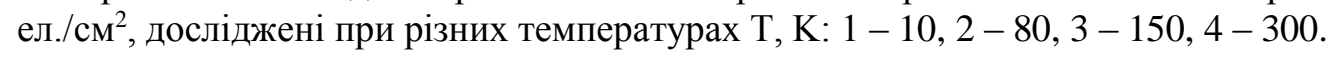

Лінії поглинання з частотами 836 та $885 \mathrm{~cm}^{-1}$ відповідають А-центру (комплекс $\mathrm{VO}_{\mathrm{i}}$ ). Даний дефект вносить в заборонену зону кремнію глибокий акцепторний рівень $E_{C}-0,17 e B$ i спостерігається в спектрах ІЧ-поглинання як в нейтральному (лінія поглинання $836 \mathrm{~cm}^{-1}$ ), так i негативно зарядженому (лінія поглинання $885 \mathrm{~cm}^{-1}$ ) станах. Лінія поглинання з частотою $865 \mathrm{~cm}^{-}$ ${ }^{1}$ відповідає комплексу $\mathrm{C}_{\mathrm{i}} \mathrm{O}_{\mathrm{i}}$, який може перебувати в нейтральному та позитивно зарядженому станах [8]. При радіаційному опроміненні вуглець, згідно з обмінним механізмом Воткінса, виштовхується власними міжвузлями 3 вузлів у міжвузлове положення 3 утворенням стабільного дефекту $\left(\mathrm{C}_{\mathrm{i}}\right)$ [9]. При дифузії у гратці міжвузловий вуглець $\left(\mathrm{C}_{\mathrm{i}}\right)$ ефективно взаємодіє з домішками, утворюючи електрично активні дефекти. У кремнії, вирощеному за методом Чохральського, $\mathrm{C}_{\mathrm{i}}$ ефективно взаємодіє 3 міжвузловим киснем $\left(\mathrm{O}_{\mathrm{i}}\right)$, в результаті чого утворюється комплекс $\mathrm{C}_{\mathrm{i}} \mathrm{O}_{\mathrm{i}}$. Даний комплекс є стабільним до температур $\mathrm{T}=600 \mathrm{~K}$ і створює в забороненій зоні кремнію глибокий рівень $E_{V}+0,35 \mathrm{eB}$. Енергія активації радіаційних дефектів для опроміненого кремнію потоком електронів $\Phi=1 \cdot 10^{17}$ ел./ $\mathrm{cm}^{2}$, визначена на основі температурних залежностей концентрації електронів (рис. 2, крива 2), виявилась рівною $E_{A}=E_{c}-(0,107 \pm 0,005) \quad \mathrm{B}$, що відповідає А-центру, який додатково модифікований домішкою фосфору (комплекс $\left.\mathrm{VO}_{\mathrm{i}} \mathrm{P}\right)$ [10]. 


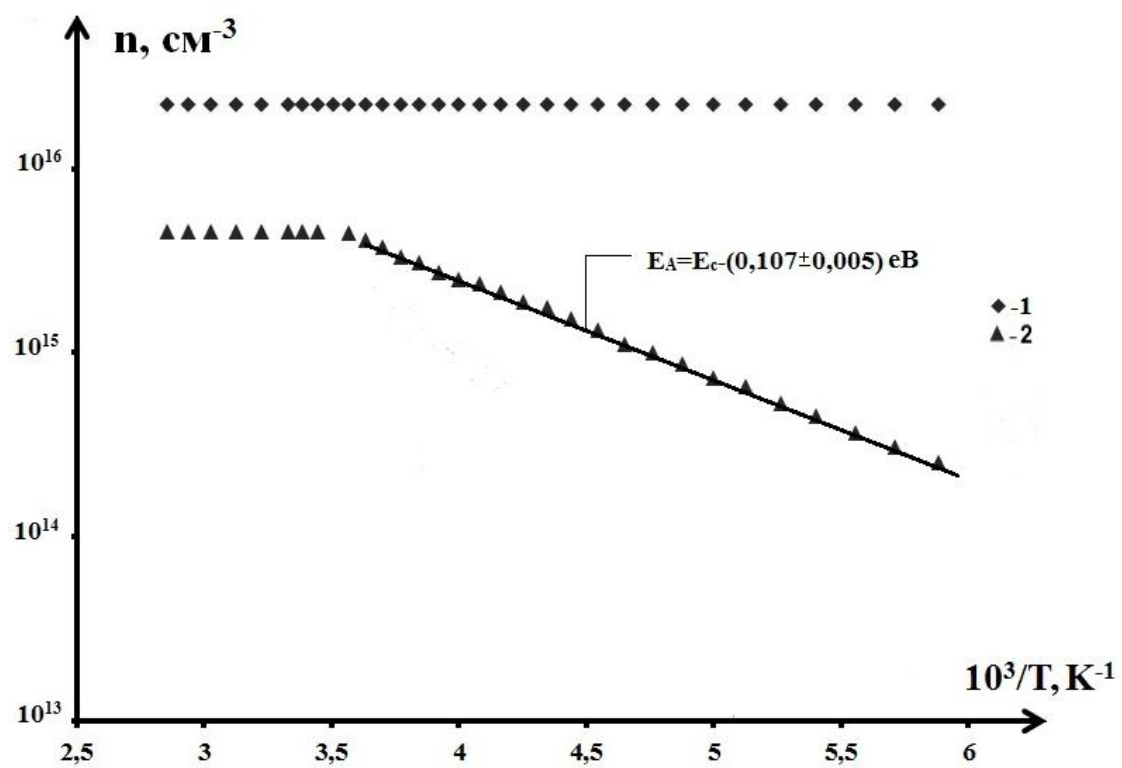

Рис. 2. Температурні залежності концентрації електронів для опромінених монокристалів кремнію потоком електронів $\Phi$, ел./см²: $1-0,2-1 \cdot 10^{17}$.

При температурах вищих за кімнатну радіаційні дефекти, які належать комплексам $\mathrm{VO}_{\mathrm{i}} \mathrm{P}$, будуть повністю іонізованим, оскільки концентрація електронів виходить на насичення (рис. 2, криві 2), а в спектрі поглинання зникає лінія $885 \mathrm{~cm}^{-1}$ (рис. 1, крива 4), що відповідає негативно зарядженому стану А-центра. Глибокий рівень $E_{V}+0,35 e B$ в даному випадку буде повністю заповнений електронами і для всього досліджуваного діапазону температур не буде проявлятись його іонізація.

Для кількісного аналізу ролі утворених радіаційних дефектів у формування нових областей фоточутливості в опроміненому кремнії потоком електронів $\Phi=1 \cdot 10^{17}$ ел./cм ${ }^{2}$ проводилась оцінка відносного збільшення фоточутливості для довжин хвиль інфрачервоного випромінювання, при яких спостерігається максимум коефіцієнта поглинання для електрично активних комплексів $\mathrm{VO}_{\mathrm{i}} \mathrm{P}$ та $\mathrm{C}_{\mathrm{i}} \mathrm{O}_{\mathrm{i}}$.

Відносне зростання коефіцієнта фото чутливості можна представити так:

$$
\delta=\frac{\alpha_{\max }}{\alpha_{0}},
$$

де $\alpha_{\max }, \alpha_{0}$ - значення коефіцієнтів поглинання в максимумі та біля основи піків в спектрі поглинання, що відповідають комплексам $\mathrm{VO}_{\mathrm{i}} \mathrm{P}$ та $\mathrm{C}_{\mathrm{i}} \mathrm{O}_{\mathrm{i}}$, відповідно

Результати розрахунків на основі виразу (1) та експериментальних даних рис. 1 представлено в в таблиці 1.

Таблиця 1.

Відносне зростання коефіцієнта фоточутливості для опромінених монокристалів кремнію електронами з енергією $12 \mathrm{MeB}$ та потоком $1 \cdot 10^{17}$ ел./см ${ }^{2}$

\begin{tabular}{|c|c|c|}
\hline \multirow{2}{*}{$\mathrm{T}, \mathrm{K}$} & \multicolumn{2}{|c|}{$\delta$} \\
\cline { 2 - 3 } & $\mathrm{C}_{\mathrm{i}} \mathrm{O}_{\mathrm{i}}$ & $\mathrm{VO}_{\mathrm{i}} \mathrm{P}$ \\
\hline 10 & 6,22 & 4,81 \\
\hline 80 & 3,61 & 3,1 \\
\hline 150 & 3,22 & 2,48 \\
\hline 300 & 2,32 & - \\
\hline
\end{tabular}

Як слідує з даної таблиці, опромінення досліджуваних зразків кремнію електронами 3 енергією $12 \mathrm{MeB}$ та потоком $1 \cdot 10^{17}$ ел./см² дозволяє підвищити коефіцієнт фоточутливості при кімнатній температурі більше як в 2 рази для довжини хвилі інфрачервоного випромінювання $\lambda \sim 11,6$ мкм, що відповідає комплексам $\mathrm{C}_{\mathrm{i}} \mathrm{O}_{\mathrm{i}}$. За рахунок поглинання ІЧ-випромінювання комплексами $\mathrm{VO}_{\mathrm{i}} \mathrm{P}$ при температурах нижчих за кімнатну 3'являється ще одна смуга 
поглинання при $\lambda \sim 11,3$ мкм, для якої, як і для смуги поглинання $\lambda \sim 11,6$ мкм, при зниженні температури відносне значення коефіцієнта фоточутливості зростає.

Висновки. Проведенні дослідження дозволили встановити природу утворених при електронному опромінені основних типів радіаційних дефектів в монокристалах кремнію, легованих домішкою фосфору $\mathrm{N}_{\mathrm{d}}=2,2 \cdot 10^{16} \mathrm{~cm}^{-3}$. На основі вимірювань ефекту Холла було показано, що для досліджуваних монокристалів кремнію $є$ досить ефективним утворення нового типу радіаційних дефектів, що належать комплексам $\mathrm{VO}_{\mathrm{i}} \mathrm{P}$. Утворення в монокристалах $\mathrm{n}-\mathrm{Si}\langle\mathrm{P}>$ при електронному опроміненні електрично активних дефектів, що належать комплексам $\mathrm{VO}_{\mathrm{i}} \mathrm{P}$ та $\mathrm{C}_{\mathrm{i}} \mathrm{O}_{\mathrm{i}}$, дозволило в широкому температурному інтервалі підвищити фоточутливість даних монокристалів.

Одержані результати можуть знайти своє практичне використання для конструювання на основі опроміненого кремнію, який легований домішкою фосфора заданої концентрації, елементів інфрачервоної техніки, таких як тепловізори, пірометри, пристрої для самонаведення на ціль снарядів і ракет, інфрачервоні приціли і т.д., для довжин хвиль $\lambda \sim 11,6$ мкм та $\lambda \sim 11,3$ мкм., які зможуть функціонувати в широкому діапазоні температур.

\section{Інформаційні джерела}

1. Fumio, S. (2012). Semiconductor Silicon Crystal Technology. Elsevier Science \& Technology, 435.

2. Sun, Y., Chmielewski, A. G. (2017). Applications of Ionizing Radiation in Materials Processing: Vol. 1. Warszawa: Institute of Nuclear Chemistry and Technology, 244.

3. Gradoboev, A. V., Simonova, A. V. (2017). Radiation technologies in the production of semiconductor devices. Physical and technical problems in science, industry and medicine: a collection of abstracts of reports of the IX International Scientific and Practical Conference, Tomsk, September 21-22, 2017. Tomsk: TPU Publishing House, 69.

4. Semeniuk, A. K. (2001). Radiation Effects in Multivalley Semiconductors. Lutsk: Nadstyr'ya, 324.

5. Murin, L. I. (1987). On the electrical activity of the Ci-Oi complex in silicon. Phys. Stat. Sol. A, 101, K107. https://doi.org/10.1002/pssa.2211010244.

6. Lavrov, E. V., Hoffmann, L., Nielsen, B. B. (1999). Local vibrational modes of the metastable dicarbon center $\left(\mathrm{C}_{\mathrm{s}}-\mathrm{C}_{\mathrm{i}}\right)$ in silicon. Physical Review B, 60, 8081-8086. https://doi.org/10.1103/PhysRevB.60.8081.

7. Vologdin, E. N., Lysenko, A. P. (1998). Integral Radiation Changes in the Parameters of Semiconductor Materials. Moscow, 94.

8. Watkins, G. D., Corbett, J. W. (1961). Defects in Irradiated Silicon. I. Electron Spin Resonance of the Si- A Center. Phys. Rev., 121, 1001-1015. https://doi.org/10.1103/PhysRev.121.1001.

9. Watkins, G.D., Brower, K. L. (1976). EPR Observation of the Isolated Interstitial Carbon Atom in Silicon. Phys. Rev. Lett. 36, 1329. https://doi.org/10.1103/PhysRevLett.36.1329.

10. Dolgolenko, A. P. (2013). Modification of radiation defects in Si and Ge by background impurity. Nuclear Physics and Atomic Energy, 14, 377 - 383.

11. Kireev, P. S. (1969). Semiconductor Physics. Moscow: Visshaja Shkola, 590.

\section{С.В. Лунёв ${ }^{1}$, Ю.А. Удовицкая ${ }^{1}$, Н.В. Хвищун ${ }^{1}$, С.А. Мороз ${ }^{1}$, В.Т. Маслюк ${ }^{2}$}

${ }^{1}$ Луцкий национальный технический университет, ул. Львовская 75, г. Луцк, 43018, Украина, luniovser@ukr.net

${ }^{2}$ Институт электронной физики НАН Украины, ул. Университетская 21., г. Ужгород, 88017, Украина, volodymyr.maslyuk@gmail.com

\section{ТЕХНОЛОГИЯ ПОЛУЧЕНИЯ ЧУВСТВИТЕЛЬНОГО ЭЛЕМЕНТА ДЛЯ ДАТЧИКА ИНФРАКРАСНОГО ИЗЛУЧЕНИЯ}

Установлено на основе измерений инфракрасной Фурье-спектроскопии и эффекта Холла, что основныли типами радиачионных дефектов в облученных электронами монокристаллах кремния являются кислородсодержащие комплексы, в состав которых входит межузловой углерод и легирующая примесь. Исследуемые монокристаллы кремния в проиессе вырашивания по методу Чохральского легировались примесью фосфора, 
концентраџией $N_{d}=2,2 \cdot 10^{16} \mathrm{~cm}^{-3}$, и в дальнейшем облучались при комнатной температуре потоком электронов $1 \cdot 10^{17}$ ел./см ${ }^{2}$ с энергией 12 МэВ. Показано, что для таких технологических условий выращивания и облучения монокристаллов кремния потоком быстрых электронов есть достаточно эффективным образование в объеме данных монокристаллов А-цеентров, дополнительно модифицированных примесью фосфора (комплексов $\left.V O_{i} P\right)$. Радиаџионная обработка исследуемых монокристаллов кремния позволила повысить их коэффициент фоточувствительности при комнатной температуре более чем в 2 раза для длины волны инфракрасного излучения ג 11,6 мкм, что соответствует поглощению радиационными дефектами, которым принадлежат комплексы $C_{i} O_{i}$ (межузловой углерод кислород). Показано, что при температурах ниже комнатной появляется еще одна полоса поглощения при $\lambda \sim 11,3$ мкм, что соответствует комплексам VO $P$. Предложенная технология получения монокристаллов кремния может быть использована для создания на их основе элементов инфракрасной техники для длин волн $\lambda$ 11,6 мкм и $\lambda \sim 11,3$ мкм., Которые смогут функиионировать в широком диапазоне температур.

Ключевые слова: монокристалль кремния, радиачионные дефекты, фототочувствительность, А-ичентры, инфракрасная Фурье-спектроскопия, эффект Холла.

\section{S.V. Luniov ${ }^{1}$, Yu. A. Udovytska ${ }^{1}$, M. V., Khvyshchun ${ }^{1}$, S.A. Moroz ${ }^{1}$, V.T. Maslyuk ${ }^{2}$}

${ }^{1}$ Lutsk National Technical University, 75Lvivska Str., Lutsk 43018, Ukraine, luniovser@ukr.net ${ }^{2}$ Institute of electronic physics NAS of Ukraine, 21Universitetska Str., Uzhghorod 88017, Ukraine, volodymyr.maslyuk@gmail.com

\section{TECHNOLOGY FOR OBTAINING A SENSITIVE ELEMENT FOR AN INFRARED RADIATION SENSOR}

In this article on the basis of measurements of infrared Fourier spectroscopy and Hall effect has been established that the main types of radiation defects in silicon single crystals, irradiated by the electrons, are oxygen-containing complexes, which include interstitial carbon and alloying impurity. Investigated silicon single crystals were doped in the growth process according to the Czochralski's method by the impurity of phosphorus, concentration $N_{d}=2,2 \cdot 10^{16} \mathrm{~cm}^{-3}$ and subsequently irradiated at room temperature by the flow of electrons of $1 \cdot 10^{17} \mathrm{el} . / \mathrm{cm}^{2}$ with the energy of $12 \mathrm{MeV}$. It has been shown that for such technological conditions of the growth and irradiation of silicon single crystals by a flow of fast electrons is a very effective the formation in the volume of these single crystals of Acenters, additionally modified by the impurity of phosphorus (VO $P$ complexes). Radiation treatment of the investigated silicon single crystals allowed to increase their photosensitivity coefficient at the room temperature more than 2 times for the wavelength of infrared radiation $\lambda \sim 11,6 \mu m$, which corresponds to the absorption by the radiation defects, which belong to the $C_{i} O_{i}$ complexes (interstitial carbon - oxygen). It has been shown that at temperatures lower than the room temperature one more absorption band appears at $\lambda \sim 11,3 \mu \mathrm{m}$, which corresponds to the $V O_{i} P$ complexes. The proposed technology of the obtaining silicon single crystals can be used to create on their basis of the elements of infrared equipment for wavelengths $\lambda \sim 11,6 \mu \mathrm{m}$ and $\lambda \sim 11,3 \mu \mathrm{m}$, which can be function in a wide range of temperatures.

Key words: silicon single crystals, radiation defects, photosensitivity, A-centers, Fourier infrared spectroscopy, Hall effect. 